\title{
Study the Anti-Toxoplasma Antibodies (IgG and IgM) in Hemodialysis Pa- tients of Abadan and Khoramshahr Cities Southwest Iran in 2011 using ELISA
}

\author{
Sharif Maraghi ${ }^{1,2, ~}{ }^{\text {, }}$, Mohammad Jafar Yadyad ${ }^{3}$, Marjan Sheikhi ${ }^{1}$, Fatemeh Shamakhteh ${ }^{1}$, \\ Seyed Mahmood Latifi ${ }^{4}$ \\ ${ }_{2}^{1}$ Abadan Arvand International Division, Ahvaz Jundishapur University of Medical Sciences. Ahvaz. IR Iran \\ 2 Infectious and Tropical Diseases Research Center, Thalassemia and Haemoglobinopathy Research Center, Ahvaz Jundishapur University of Medical Sciences, Ahvaz, IR Iran \\ 3 Infectious Diseases Department, Abadan Arvand International University of Medical Sciences, Abadan, IR Iran \\ 4 Department of Biostatistics and Epidemiology. School oh Health. Diabetes Research Center. Ahvaz Jundishapur University of Medical Sciences, Ahvaz, IR Iran \\ *Corresponding author: Sharif Maraghi, Department of Parasitology and Mycology, Abadan Arvand International University, Abadan, IR Iran; Infectious and Tropical Diseases Re- \\ search Center, Thalassemia and Haemoglobinopathy Research Center, Jundishapur University of Medical Sciences, Ahvaz, IR Iran. Tel: +98-6113330678, Fax: +98-6112231326, E-mail: \\ maraghis@gmail.com.
}

Received: July 11, 2012; Revised: September 28, 2012; Accepted: September 30, 2012

\begin{abstract}
Background:Toxoplasmosis is a worldwide disease caused by an obligate intracellular protozoan, Toxoplasma gondii and can cause severe infections in immune-compromised individuals.

Objectives: The aim of this study was to determinate the anti- Toxoplasma antibodies in hemodialysis patients of Abadan and Khoramshahr, Southwest of Iran.

Materials and Methods: Sera of 150 patients (test group) aged 21 to 87 years referred regularly to hemodialysis departments in Abadan and Khoramshahr cities, and 150 healthy individuals (control group) were examined for anti-Toxoplasma (IgG and IgM) antibodies using ELISA kits and the results were analyzed using Chi-square and fisher exact test.

Results: 61 (40.67\%) out of 150 sera of patients were positive, 6 (4\%) were borderline and 83 (55.33\%) were negative for anti-Toxoplasma IgG. For anti-Toxoplasma IgM, 13 (8.67\%) of 150 were positive, 21 (14\%) were borderline and 116 (77.33\%) were negative. In control group 39 (26\%) of 150 individuals were positive, 14 (9.33\%) were borderline and 97 (64.67\%) were negative for anti- Toxoplasma IgG. In the sera of individuals in control group, anti-Toxoplasma IgM was not detected. In hemodialysis patients, 7 (4.66\%) cases were positive for anti-Toxoplasma IgG and IgM and $8(5.33 \%)$ cases were IgG positive and IgM borderline. There were significant differences in IgG and IgM level of the test and control groups $(\mathrm{P}<0.05)$

Conclusions: Hemodialysis patients are high risk group for toxoplasmosis and should be tested periodically to prevent the dissemination of toxoplasmosis during dialysis.
\end{abstract}

Keywords: Toxoplasma gondii; Haemodialysis; Immunoglobulines

\section{Background}

Toxoplasmosis is a cosmopolitan disease caused by an intracellular protozoa, Toxoplasma (1). The parasite infects a wide range of birds and mammals including humans are known as intermediate hosts. The definitive host from Toxoplasma are the members of Felidae family that the Toxoplasma sexual cycle takes place in the intestinal epithelium of those hosts (2). Human and animals are infected through the ingestion of contaminated vegetables, water and soil with oocyst defecated by definitive host or consumption of raw or uncooked meat containing Toxoplasma tissue cyst. Toxoplasmosis can transmit via the placenta of infected pregnant woman which acquire toxoplasmosis during the pregnancy $(3,4)$.

Toxoplasma gondii is an opportunistic parasite which causes non- symptomatic infections in immune- competent individuals around the world (5). Generally, toxoplasmosis is depended on many factors such as the amount of sanitation, humidity, temperature, contact with soil, domestic animals (6) that varied from 0 to $95 \%$ (7). The prevalence of $T$. gondii in USA is about $22.5 \%$ (3), in South Korea from 0.27 to $12.9 \%$ (8), and in Izmir Turkey, 23.1\% (9). According to the report of Assmar et al., the seroprevalence of T. gondii in Iran is 51.8\% (10), while the study of Salahi Moghadam and Hafizi in south region of Tehran indicated that $68.4 \%$ of the population are seropositive (11). Acute toxoplasmosis in $80 \%$ of healthy hosts is asymptomatic and only $20 \%$ of adults and children revealed a symptomatic infection (12). Although existence of Toxoplasma tissue cysts in hosts may contribute to mainte- 
nance of immunity against reinfection, but their presence may also cause symptomatic toxoplasmosis under certain condition, especially in immune- compromised patients and infant with congenital toxoplasmosis (4).

\section{Objectives}

The objective of this study was to determinate the antiToxoplasma (IgG and IgM) antibodies in hemodialysis patients of Abadan and Khoramshahr cities, Southwest Iran in 2011.

\section{Materials and Methods}

Sera of 150 patients (test group) aged 21 to 87 years regularly referred to hemodialysis departments of Shahid Beheshti hospital in Abadan and Fatemate- mat Alzahra in Khoramshahr cities, and 150 healthy individuals (control group) with the mentioned criteria and without renal disease and normal biochemical tests including blood urea nitrogen (BUN) and Creatine were collected and examined for anti- Toxoplasma (IgG and IgM) antibodies us- ing ELISA kits (Orgenium Laboratories-Finland) and the results were analyzed using Chi-square and fisher exact test.

\section{Results}

104 patients including 52 (50\%) male and 52 (50\%) female with the mean age of 46.43 years were from Abadan and 46 patients, 29 (63\%) male and 17 (37\%) with the mean age of 50.58 years were from Khoramshahr. Table 1 shows the prevalence of IgG and IgM in hemodialysis patients and healthy individuals, respectively based onthe reference value of each immunoglobulin. The prevalence of anti-Toxoplasma antibodies (IgG and IgM) of hemodialysis patients in Abadan and Khoramshahr are separately shown in Table 2.

$\operatorname{Six}(4.66 \%)$ cases were positive for both anti-Toxoplasma IgG and IgM and 10 (6.7\%) cases were IgG positive and IgM borderline in hemodialysis patients. Comparison of immunoglobulin level of hemodialysis patients in Abadan and Khoramshahr are summarized in Table 3.

Table 1. Prevalence of Anti- Toxoplasma IgG and IgM of Hemodialysis Patients and Healthy Individuals in Abadan and Khoramshahr Cities in 2011

\begin{tabular}{|c|c|c|c|c|}
\hline \multirow[t]{2}{*}{ Group } & \multicolumn{4}{|c|}{ IgG } \\
\hline & IgG Positive & IgG Borderline & IgG Negative & Reference Value \\
\hline Test & $61(40.67 \%)$ & $6(4 \%)$ & $83(55.33 \%)$ & $\begin{array}{l}<0.8 \text { : negative, } 0.8-1.1 \text { : borderline, } 1-4 \text { : positive, }>4 \text { : } \\
\text { high positive }\end{array}$ \\
\hline \multirow[t]{3}{*}{ Control } & $39(26 \%)$ & $14(9.33 \%)$ & $97(64.67 \%)$ & $\begin{array}{l}<0.8 \text { : negative, } 0.8-1.1 \text { : borderline, } 1-4 \text { : positive, }>4 \text { : } \\
\text { high positive }\end{array}$ \\
\hline & \multicolumn{4}{|c|}{ IgM } \\
\hline & IgM Positive & IgM Borderline & IgM Negative & Reference Value \\
\hline Test & $13(8.67 \%)$ & $21(14 \%)$ & $116(77.33 \%)$ & $<0.8$ : negative, 0.8 - 1.1: borderline, $\geq 1.11$ : positive \\
\hline Control & 0 & 0 & $150(100 \%)$ & $<0.8$ : negative, $0.8-1.1$ : borderline, $\geq 1.11$ : positive \\
\hline
\end{tabular}

Table 2. Prevalence of Anti-Toxoplasma Antibodies (IgG and IgM of Hemodialysis Patients in Abadan and Khoramshahr in 2011

\begin{tabular}{lllll}
\hline Abadan & IgG positive & IgG borderline & IgG negative & Total \\
& $45(43.3 \%)$ & $3(2.9 \%)$ & $56(33.8 \%)$ & 104 \\
\hline Khoramshahr & IgM positive & IgM borderline & IgM negative & \\
& Ig(9.62\%) & $7(15.22 \%)$ & $80(76.92 \%)$ & \\
& IgG positive & IgG borderline & IgG negative & 46 \\
\hline & Ig(34.78) & $3(6.52 \%)$ & $27(58.7 \%)$ & \\
\hline
\end{tabular}


Table 3. The Status of IgG and IgM and the Comparison of Immunoglobulins in Hemodialysis Patients in Abadan and Khoramshahr in 2011

\begin{tabular}{|c|c|c|c|c|c|c|c|c|c|}
\hline \multirow[t]{2}{*}{ City } & \multicolumn{8}{|c|}{$\operatorname{Ig}^{\mathrm{a}}$} & \multirow[t]{2}{*}{ Total } \\
\hline & $\begin{array}{l}\text { Ig G pos, Ig } \\
\text { M pos }\end{array}$ & $\begin{array}{l}\text { Ig G pos, } \\
\operatorname{Ig~M~B~}^{\mathrm{a}}\end{array}$ & $\begin{array}{l}\text { Ig G pos, } \\
\text { Ig M neg }\end{array}$ & $\begin{array}{l}\text { Ig G neg, } \\
\text { Ig M B }\end{array}$ & $\begin{array}{l}\text { Ig G neg, Ig } \\
\text { M neg }\end{array}$ & $\begin{array}{l}\text { Ig M pos, } \\
\text { Ig G B }\end{array}$ & $\begin{array}{l}\text { Ig M neg, } \\
\text { Ig G B }\end{array}$ & $\begin{array}{l}\text { Ig M pos, Ig G } \\
\text { neg }\end{array}$ & \\
\hline Abadan & 6 & 6 & 34 & 8 & 42 & 0 & 4 & 4 & 104 \\
\hline $\begin{array}{l}\text { Khoram- } \\
\text { shahr }\end{array}$ & 0 & 4 & 12 & 3 & 22 & 1 & 2 & 2 & 46 \\
\hline Total & 6 & 10 & 46 & 11 & 64 & 1 & 6 & 6 & 150 \\
\hline
\end{tabular}

a Abbreviations: Ig, Immunoglobulins; B, Borderline

\section{Discussion}

Toxoplasmosis in immune-competent individuals revealed an excellent prognosis, and lymphadenopathy and other symptoms are generally revealed within few weeks of infection in adults (4). Most cases of toxoplasmosis, in immune- compromised patients, are a consequence of latent infection and reactivation (13). In this study, anti- Toxoplasma antibodies (IgG and IgM) in hemodialysis patients (40.67\% and $8.6 \%$, respectively) were significantly higher than those in control group (26\% and $0 \%$, respectively) $(\mathrm{P}<0.05) .6(4.66 \%)$ cases of hemodialysis patients were positive for both IgG and IgM antibodies which gives the impression that these patients might have the acute toxoplasmosis. On the other hand 10 (6.7\%) cases of patients were positive for anti- Toxoplasma IgG and their level of IgM was on the borderline cut off. These patients might be in the primary stage of acute toxoplasmosis and should be followed and appropriate measurements should be taken to prevent the dissemination of disease, since in uremic renal failure patients humoral and cellular immunity are suppressed (14) and in such patients weakened cell functions have been reported (15), absolute number of circulating $\mathrm{T}$ - cells will reduce and suppressor cells increase and hemodialysis is unable to restore the impairment of the immune system in chronic renal failure (CRF) (16). Some factors such as antibacterial therapy (17), vitamin B6 deficiency (15) and activation of cellular immune suppressor mechanisms (18) seem to be effective on the incidence of uremic chronic renal failure and increase the infection possibilty among dialysis patients (19).

In this study the prevalence of IgG was higher than the results reported by Abbas et al. in Egypt (20) and lower in Ocak et al. in Turkey (21). In the study of Yazar et al. in turkey (22), the prevalence of anti-Toxoplasama IgG in hemodialysis patients (56.06\%) was higher than our study (40.67\%), while anti-Toxoplasma IgM in the present study (8.67\%) was higher than Yazar et al. study (1.7\%), also $14 \%$ of our hemodialysis patients showed IgM borderline titer. In a study by Aufy et al.in Egypt, the prevalence of antiToxoplasma antibody, IgG (56.7\%) and IgM (16.6\%) were higher than our study. In Aufy's study the IgG and IgM levels in the sera of renal transplant patients were high as well (23). Prevalence of anti- Toxoplasma antibodies, IgG (59.1\%) was higher, while IgM (6.8\%) was in consistent with the study reported by Solhjoo et al. in hemodialysis patients from Jahrom, South Iran (24), while in Saki et al. study on 280 sera of end stage renal disease (ESRD) patients and 100 controls in Ahvaz city, 29.8\% of patients and $26 \%$ of the control group were IgG positive and for IgM, $7.9 \%$ of the patients and $4 \%$ of the control group were IgM positive, which is not compatible with our study(25). The results of this study indicated that, hemodialysis patients are considered as a risk group for toxoplasmosis infections and it is recommended that the patients with chronic renal failure who undergo a long term of hemodialysis and are candidate for renal transplantation and kidney recipient should be screened for toxoplasmosis through the hemodialysis procedure to prevent the dissemination of infection.

\section{Acknowledgements}

This research with the code of B-90/035 was financially supported by Vice chancellor of research and technology of Abadan Arvand International University of Medical Sciences and Ahvaz Jundishapur University of Medical Sciences which is appreciated. The authors like to thank the Infectious and Tropical Diseases Research Center and Dr. $\mathrm{H}$. Javaherizadeh for his critical supports and helps.

\section{Authors' Contribution}

Sharif Maraghi, 30\%; Mohammad Jafar Yadyad, 10\%; Marjan Sheikhi, 25\%; Fatemeh Shamakhteh, 25\%; Seyed Mahmood Latifi, $10 \%$.

\section{Financial Disclosure}

The authors declare no financial disclosure.

\section{Funding/Support}

None declared. 


\section{References}

1. Chen XG, Tan F. [Toxoplasma gondii: past, present and future]. Zhongguo Ji Sheng Chong Xue Yu Ji Sheng Chong Bing Za Zhi. 2009;27(5):426-31.

2. Torda A. Toxoplasmosis. Are cats really the source? Aust Fam Physician. 2001;30(8):743-7.

3. Montoya JG, Liesenfeld O. Toxoplasmosis. Lancet. 2004;363(9425):1965-76.

4. Remington JS. Infectious disease of the fetus and newborn infant. 6 ed. Philadelphia: Elsevier Saunders; 2006.1313 pp.

5. Sensini A. Toxoplasma gondii infection in pregnancy: opportunities and pitfalls of serological diagnosis. Clin Microbiol Infect. 2006;12(6):504-12.

6. Kamani J, Mani AU, Egwu GO, Kumshe HA. Seroprevalence of human infection with Toxoplasma gondii and the associated risk factors, in Maiduguri, Borno state, Nigeria. Ann Trop Med Parasitol. 2009;103(4):317-21.

7. Asthana SP, Macpherson CN, Weiss SH, Stephens R, Denny TN, Sharma RN, et al. Seroprevalence of Toxoplasma gondii in pregnant women and cats in Grenada, West Indies. J Parasitol. 2006;92(3):644-5.

8. Shin DW, Cha DY, Hua QJ, Cha GH, Lee YH. Seroprevalence of Toxoplasma gondii infection and characteristics of seropositive patients in general hospitals in Daejeon, Korea. Korean J Parasitol. 2009;47(2):125-30.

9. Altintas N, Yolasigmaz A, yazar S, Sakru N, Kitapqioglu G. Investigation of Toxoplasma antibodies in residence of central Izmir and surrounding rural area. Act Parasitol Tur. 1998;22:229-32.

10. Assmar M, Amirkhani A, Piazak N, Hovanesian A, Kooloobandi A, Etessami R. [Toxoplasmosis in Iran. Results of a seroepidemiological study]. Bull Soc Pathol Exot. 1997;90(1):19-21.

11. Salahi-Moghaddam A, Hafizi A. A serological study on Toxoplasma gondii infection among people in south of Tehran, Iran. Korean J Parasitol. 2009;47(1):61-3.

12. Hokelek M. Toxoplasmosis. eMedicine Infectious Diseases;2009.
13. Luft BJ, Remington JS. Toxoplasmic encephalitis in AIDS. Clin Infect Dis. 1992;15(2):211-22.

14. Wilson WEC, Kirkpatric CH, Talmage DW. Suppression of immunologic responsiveness in uremia. Int Med.1965;62(1):1-14.

15. Dobbelstein $H$. Immune system to uremia. Nephron. 1976;17(6):409-14.

16. Schollmeyer P, Bozkurt F. The immune status of the uremic patient: hemodialysis vs CAPD. Clin Nephrol.1988;30 Suppl 1:S37-40.

17. Munster AM, Loadholdt CB, Leary AG, Barnes MA. The effect of antibiotics on cell-mediated immunity. Surgery. 1977;81(6):692-5.

18. Hanicki Z, Cichocki T, Sarnecka-Keller M, Klein A, Komorowska Z Influence of middle-sized molecule aggregates from dialysate of uremic patients on lymphocyte transformation in vitro. Nephron. 1976;17(1):73-80.

19. Vanholder R, Dell'Aquila R, Jacobs V, Dhondt A, Veys N, Waterloss MA, et al. Depressed phagocytosis in hemodialyzed patients: in vivo and in vitro mechanisms. Nephron.1993;63(4):409-15

20. Abbas MM, Zaki M, Afify NA. Prevalence of Toxoplasma gondii and cytomegalovirus antibodies in patients with chronic renal failure. J Egypt Soc Parasitol.1996;26(3):671-6.

21. Ocak S, Duran N, Eskiocak AF, Aytac H. Anti-Toxoplasma gondii antibodies in hemodialysis patients receiving long-term hemodialysis therapy in Turkey. Saudi Med J. 2005;26(9):1378-82.

22. Yazar S, Demirtas F, Yalcin S, Yaman O, Tokgoz B, Utas C, et al. AntiToxoplasma gondii antibodies in haemodialysis patients with chronic renal failure. Yonsei Med J. 2003;44(2):288-92.

23. Aufy SM, Mahgoub AM, Saadi MG, Adel Elmallawany M. Serological detection of Toxoplasma gondii in chronic renal failure patients and renal transplant recipients. J Egypt Soc Parasitol. 2009;39(3):943-50.

24. Solhjoo K, Jahromi AS, Parnian-Rad A. Anti-Toxoplasma gondii Antibodies in Haemodialysis Patients. Am J Inf Dis. 2010;6(1):13.

25. Saki J, Khademvatan S, Soltani S, Shahbazian H. Detection of toxoplasmosis in patients with end-stage renal disease by enzymelinked immunosorbent assay and polymerase chain reaction methods. Parasitol Res. 2013;112(1):163-8. 